J. Clin. Chem. Clin. Biochem.

Vol. 20, 1.982, pp. 217-220

\title{
Determination of Urinary Vanilmandelic Acid and Homovanillic Acid by High Performance Liquid Chromatography with Amperometric Detection
}

\author{
By W. Bauersfeld, U. Diener, E. Knoll, D. Ratge and H. Wisser \\ Department of Clinical Chemistry, Robert-Bosch-Krankenhaus, Stuttgart (FRG)
}

(Received July 9/December 10, 1981)

Summary: A method was developed for the simultaneous determination of urinary vanilmandelic acid and homovanillic acid, which included a two step prepurification and a reversed-phase high-performance liquid chromatography with amperometric detection. Conditions were evaluated for performing measurements with the amperometric detector free from electric interference.

The method was linear between 2.5 and $100 \mu \mathrm{mol} / \mathrm{l}$ vanilmandelic acid and homovanillic acid with good precision (CV always less than $10 \%$ ).

The correlation between the present determination of vanilmandelic acid and the procedure of Pisano et al. ((1962) Clin. Chim. Acta 7, 285-291) was very good ( $\mathrm{r}=0.931)$. No interfering substances could be detected.

\section{Bestimmung von Vanillinmandelsäure und Homovanillinsäure im Urin mit Hochdruckflüssigkeitschromatographie und amperometrischer Detektion}

Zusammenfassung: Eine neue Methode zur gleichżeitigen Bestimmung von Vanillinmandelsäure und Homovanillinsäure im Urin wurde erarbeitet. Sie basiert auf der Kombination von HPLC und amperometrischer Detektion sowie einer zweistufigen Vortrennung. Es wurden die Versuchsbedingungen untersucht, die eine störungsfreie Messung mit dem amperometrischen Detektor ermöglichen.

Das Verfahren ist von 2,5 bis $100 \mu \mathrm{mol} / 1$ Vanillinmandelsäure und Homovanillinsäure linear, wobei der Variationskoeffizient über den gesamten Bereich kleiner äls $10 \%$ ist. Die Korrelation der Bestimmung der Vanillinmandelsäure mit der Methode von Pisano et al. ((1962) Clin. Chim. Acta 7, 285-291) ist hoch $(\mathrm{r}=0,931)$. Störende Substanzen konnten nicht festgestellt werden.

\section{Introduction}

The photometric determination of 3-methoxy-4-hydroxymandelic acid (vanilmandelic acid) by the procedure of Pisano $(1,2)$ is very time consuming and necessitates a large number of extraction steps. Therefore, in the last few years several methods have been developed to improve the vanilmandelic acid determination. Some of these methods were based on high-performance liquid chromatography with amperometric detection. W. Rich et al. (3) used equipment comprising two pumps, two conductivity detectors and five columns with an overall length of $800 \mathrm{~mm}$. By using this expensive equipment, the authors were able to measure urinary vanilmandelic acid without any prepurification.

An equally simple procedure, using a less expensive equipment was described by Morrisey \& Shihabi (4). But it was not possible to reproduce their experiments. A lot of unknown substances interfered with the measurement of vanilmandelic acid and some substances were not removed from the column until several hours after the injection of the urine samples.

The present method for vanilmandelic acid determinations is simple and reliable. The equipment for highperformance liquid chromatography consists only of one pump, one column and one detector. The application of the amperometric detector proved to be simpler than the fluorometric detection. But some special provisions had to be taken to get good measurements with a high signal-to-noise ratio.

The prepurification (ethyl acetate extraction followed by small column chromatography on diethylaminoethylcellulose) was absolutely necessary. This could be done in such a way, that vanilmandelic acid and 3-methoxy-4hydroxyphenyl acetic acid (homovanillic acid), could be eluted in the same fraction and subsequently determined simultaneously by HPLC. The simultaneous determination of vanilmandelic acid and homovanillic acid is desirable as could be shown by La Brosse et al. (5) in a 
study of 258 patients with neuroblastoma. They found a diagnostic sensitivity of $76.4 \%$ for homovanillic acid, $69.4 \%$ for vanilmandelic acid and $81.8 \%$ for the combination of both determinations. It was evident that the diagnostic sensitivity had clearly increased by the simultaneous determination of both acids. In the method described here, this improvement in diagnostic sensitivity can be achieved by using one single analytical procedure.

\section{Materials and Methods}

Equipment

\section{High-performance liquid chromatography}

A Model 6000 A pump (Waters Associates Inc.,.Königstein, Tạnus) was used to deliver the solvent through a $300 \times 3.9 \mathrm{~mm}$ (i.d.) column of $\mu$ Bondapak $\mathrm{C18}, 10 \mu \mathrm{m}$ average particle size (Waters Associates Inc., Königstein, Taunus). The samples were introduced through a $20 \mu \mathrm{lloop}$ injector (Model 7125, Rheodyne Inc., Berkeley, California).

$$
1
$$

\section{Electrochemical detection}

The effluent was monitored with a glassy carbon electrode cell, a Ag/AgCl-reference electrode and an amplifier LC 4 (Bioanalytical Systems Inc., West Lafayette, In.). The chromatograms were plotted with a Servogor 210 recorder (BBC Goerz, Wien).

\section{Electrical interference suppression}

The electrochemical detection was realized in a Faraday cage by a flowing potential measurement. The cage surrounded both the detection cell and the amplifier. The connection wire to the recorder was covered with a tube produced from a metal fabric. Remaining interferences were eliminated by a double- $L$ lowpass-filter $(100 \mathrm{k} \Omega, 3.3 \mu \mathrm{F})$ near the input of the recorder. Moreover a line filter is required, constructed with VDR-varistors (Type 232259413912 Valvo, Hamburg) and two wide-band filters (Type 9764 Valvo, Hamburg) connected in series.

\section{Prepurification}

Ethyl acetate extraction was carried out in $20 \mathrm{ml}$ glass tubes and column chromatography in small polyethylene columns (9 mm i.d.) (QS-Q, Isolab Inc., Akron, Ohio). The filling height of diethyl-aminoethyl-cellulose was $30 \mathrm{~mm}$.

\section{Mechanization}

Programmed sample injection and electrical evaluation was done with a WISP $710 \mathrm{~B}$, and automatic evaluation was performed with Data Module (Waters Association, Königstein, Taunus).

\section{Chemicals and reagents}

All reagents were of analytical grade and purchased from Merck AG. Darmstadt, unless otherwise stated.

\section{Ethyl acetate extraction}

$6 \mathrm{~mol} / 1$ hydrochloric acid, sodium chloride, ethyl acetate, $0.2 \mathrm{~mol} / 1$ tris(hydroxymethyl)aminomethane solution (solution A).

\section{Column chromatography}

Diethylaminoethyl-cellulose (Servacel DEAE 32, Serva, Heidelberg), $50 \mathrm{mmol} / 1$ tris-buffer $\mathrm{pH} 8.1$ (solution $\mathrm{B}$ ), $0.3 \mathrm{~mol} / \mathrm{l}$ sodium chloride in $10 \mathrm{mmol} / 1$ hydrochloric acid (solution $\mathrm{C}$ ).

\section{Regeneration of diethylaminoethyl-cellulose}

$3 \mathrm{~mol} / 1$ sodium chloride in $10 \mathrm{mmol} / 1$ sodium hydroxide solution (solution D).

\section{Mobile phase}

$200 \mathrm{ml}$ of $50 \mathrm{mmol} / 1$ citric acid and $800 \mathrm{ml}$ of $50 \mathrm{mmol} / 1$ disodium phosphate were mixed, filtered (Millipore HA, $0.45 \mu \mathrm{m}$ pore size, Millipore Corp., Bedford, Massachusetts) and degassed for $10 \mathrm{~min}$. Then 20 to $60 \mathrm{ml}$ acetonitrile were added and again degassed for $3 \mathrm{~min} .60 \mathrm{ml}$ of acetonitrile were added, if new columns were used, resulting in a retention time of $8 \mathrm{~min}$ for homovanillic acid. The retention time decreased with increasing age of the column. This could satisfactorily be compensated by the reduction of the acetonitrile concentration to $20 \mathrm{ml} / 1$ eluent. Thus the retention time of $8 \mathrm{~min}$ for homovanillic acid could be maintained.

\section{Standard solution (solution E)}

A solution of $20 \mu \mathrm{mol} / 1$ vạnilmandelic acid' (Serva, Heidelberg) and homovanillic acid (Fluka $A G$, Neu=Ulmin) wạs prepared by dilution of a stock solution with distilled water.

\section{Stock solution}

$0.1 \mathrm{mmol}$ vanilmandelic acid and $0.1 \mathrm{mmol}$ homovanillic acid were dissolved in $80 \mathrm{ml}$ water, acidified with $1 \mathrm{ml}$ of $6 \mathrm{moll} / \mathrm{l}$ hydrochloric acid and filled up to $100 \mathrm{mil}$ with water. This solution was stable for several months if stored at $-14^{\circ} \mathrm{C}$.

\section{Urine pool}

A large amount of urine was acidified with $10 \mathrm{ml}$ of $6 \mathrm{~mol} / \mathrm{l}$ hydrochloric acid to 11 of urine, thoroughly mixed, divided in portions of $50 \mathrm{ml}$ and stored at $-14^{\circ} \mathrm{C}$.

\section{Methodology}

Standard solution (E) and urine samples $(F)$ wèrè measurured according to the following procedure: ca. $300 \mathrm{mg}$ of sodium chloride and $100 \mu \mathrm{l}$ of $6 \mathrm{~mol} / \mathrm{l}$ hydrochloric acid were added to $1 \mathrm{ml}$ of a sample (E or F) in $20 \mathrm{ml}$ glass tubes, and mixed for a short time. After adding $8 \mathrm{ml}$ of ethyl acetate the mixture was shaken for about $30 \mathrm{~s}$ on a Vortex-mixer and centrifuged at $200 \mathrm{~g}$ for $5 \mathrm{~min} .6 \mathrm{ml}$ of the organic upper layer were transferred into a second glass tube and extracted with $3 \mathrm{ml}$ of tris solution (A). Shaking and centrifugation was performed as described before. Now the organic upper layer was aspirated and discarded.

\section{Column chromatography}

$2 \mathrm{ml}$ of the lower aqueous layer were applied on the top of the bed of a diethylaminoethyl-cellulose column. Then the gel was washed in two steps. The first washing was carried out with $2 \mathrm{ml}$ of tris buffer (B) and the second with $1.5 \mathrm{ml}$ of sodium chloride solution (C). Subsequently vanilmandelic acid and homovanillic acid were eluted with $2 \mathrm{ml}$ of sodium chloride solution (C). The eluate can be stored at $-14^{\circ} \mathrm{C}$ until quantitative determination by high-performance liquid chromatography and amperometric detection. It is stabile for several weeks under these conditions.

\section{High-performance liquid chromatography and amperometric detection}

The fraction containing vanilmandelic acid and homovànillic acid was diluted 1:2 with the mobile phase used for the highperformance liquid chromatography. $20 \mu \mathrm{l}$ of these dilutions were injected every $30 \mathrm{~min}$. In most urines interferring substances were eluted after $18 \mathrm{~min}$. However, in two urine samples one peak was observed after $28 \mathrm{~min}$. So it wäs necessary to wait $30 \mathrm{~min}$ for the next injection. But it was possible to inject the standard solution in the last $10 \mathrm{~min}$ of each chromatogram to test the sensitivity of the detector. The flow rate of the eluent was $0.9 \mathrm{ml} / \mathrm{min}$. The amperometric detector was set to an oxidizing potential of $+650 \mathrm{mV}$, a sensitivity of $10 \mathrm{nA} / \mathrm{V}$, a filtering of $0.5 \mathrm{~s}$ and an offset between 3 and $20 \mathrm{nA}$.

\section{Evaluation}

The concentration of vanilmandelic acid and homovanillic acid was calculated by comparison with the peak height obtained for the standard solution.
$+7$ 


\section{Regeneration of the diethylaminoethyl-cellulose}

With the aid of $50 \mathrm{ml}$ pin up funnels the diethylaminoethylcellulose was washed successively with $50 \mathrm{ml}$ of alkaline sodium chloride solution (D), $25 \mathrm{ml}$ of acidic sodium chloride solution (C) and $50 \mathrm{ml}$ tris-buffer (B).

\section{Working period}

If the oxidizing potential was switched off and the flow rate of the eluent set to $0.5 \mathrm{ml} / \mathrm{min}$ through the night, polishing of the electrode was only necessary in intervals of more than three days. If the column was washed for $2 \mathrm{~h}$ with $300 \mathrm{ml} / \mathrm{l}$ aqueous methanol after each series of measurements, it could be used for more than half a year.

\section{Results and Discussion}

Improvement of measuring system

\section{Baseline noise}

If pump and injection system was rendered passive (10 min with $3 \mathrm{~mol} / 1$ nitric acid) and mobile phase was thoroughly degassed and kept at $40^{\circ} \mathrm{C}$ in a water bath, a signal-to-noise ratio of more than 100:1 (40 dB) could be achieved. Thus no electric interferences could be detected.

\section{Relative peak height}

In the course of the preseparation the original urine was diluted by $1: 8$. If dilution was lower, peak height increased, but stability of peak height was affected. If dilution was higher, the signal-to-noise ratio decreased.

\section{Prepurification}

The column chromatography on diethylaminoethyl: cellulose is necessary in order to achieve a satisfactory specificity of the method. Especially the 5-hydroxyindole-3-acetic acid would interfere with homovanillic acid if this separation step were omitted. Homovanillic acid and 5-hydroxyindole-3-acetic acid separation improved with increasing sält concentrations. However, if the concentration of salt was greater than $0.3 \mathrm{~mol} / 1$ the separation could not be done with good reproducibility, because increasing concentrations of salt result in a decrease of retention.

\section{Mechanization}

The measuring system was suitable for programmed sample injection combined with electronic evaluation. The fluctuations of pressure following automatic sample injection caused some peaks in the first few minutes after sample injection. But these peaks did not interfere with the detection of vanilmandelic acid and homovanillic acid.

\section{Reliability criteria of the method}

\section{Precision}

The reproducibility of the method was evaluated by multiple determinations of a pooled urine (E), containing $23.1 \mu \mathrm{mol} / 1$ vanilmandelic acid and $24.4 \mu \mathrm{mol} / 1$ homovanillic acid. The within-run precision was estimated by $n=8$ measurements to $\mathrm{s}=0.9 \mu \mathrm{mol} / 1$ vanilmandelic acid and $s=2.5 \mu \mathrm{mol} / 1$ homovanillic acid (tab. 1). The between-run precision - measured at 7 days - resulted in $\mathrm{s}=1.9 \mu \mathrm{mol} / 1$ vanilmandelic acid and $\mathrm{s}=2.5 \mu \mathrm{mol} / 1$ homovanillic acid.

Tab. 1. Precision.

\begin{tabular}{llcc}
\hline & & $\begin{array}{l}\text { Vanil- } \\
\text { mandelic } \\
\text { acid }\end{array}$ & $\begin{array}{l}\text { Homo- } \\
\text { vanillic } \\
\text { acid }\end{array}$ \\
\hline Within-run & $\mathrm{n}$ & 8 & 8 \\
& $\overline{\mathrm{x}}(\mu \mathrm{mol} / 1)$ & 23.1 & 24.4 \\
$\mathrm{~s}(\mu \mathrm{mol} / 1)$ & 0.9 & 2.5 \\
Between run & $\mathrm{CV}(\%)$ & 3.9 & 10.1 \\
& $\mathrm{n}$ & 7 & 7 \\
& $\overline{\mathrm{x}}(\mu \mathrm{mol} / \mathrm{l})$ & 21.2 & 21.2 \\
& $\mathrm{~s}(\mu \mathrm{mol} / 1)$ & 1.9 & 2.5 \\
& $\mathrm{CV}(\%)$ & 8.8 & 11.6 \\
\hline
\end{tabular}

\section{Recovery}

The recovery was determined by adding known amounts $(20.7 \mu \mathrm{mol} / 1$ vanilmandelic acid and $32.7 \mu \mathrm{mol} / 1$ homovanillic acid) to a urine pool. An average recovery $(n=12)$ of $99.5 \%(s=5.7 \%)$ and $102.3 \%(s=6.3 \%)$ was found for vanilmandelic acid and homovanillic acid, respectively.

\section{Linearity}

The calibration curve of the assay was linear between 2.5 and $100 \mu \mathrm{mol} / 1$. The correlation coefficient between the calculated and the measured concentrations was determined in twelve measurements. The values of vanilmandelic acid and homovanillic acid were $r=0.995$ and $\mathrm{r}=0.993$.

\section{Specificity}

Specificity was tested by adding potential interferants to a urine pool. No interferences could be seen with any of the tested compounds. The elimination of various interferants during the prepurification was studied by high performance liquid chromatographic measurements of their concentrations in all fractions.

Dopa $(\leqslant 4.0 \mu \mathrm{mol} / 1)$, dopamine $(\leqslant 8.3 \mu \mathrm{mol} / 1)$, metanephrine $(\leqslant 3.8 \mu \mathrm{mol} / \mathrm{l})$ and normetanephrine $(\leqslant 4.8 \mu \mathrm{mol} / 1)$ were well separated by ethyl acetate extraction and did not interfere with the determination 
of vanilmandelic acid or homovanillic acid. Phenolic alcohols like 3-methoxy-4-hy'droxy-phenylglycol $(\leqslant 31.7 \mu \mathrm{mol} / \mathrm{l})$ were extracted and reextracted in small amounts, but they did not adsorb on diethylaminoethylcellulose and therefore passed through the column before vanilmandelic acid was eluted. Heterocyclic acids like 5-hydroxyindole-3-acetic acid $(\leqslant 72.6 \mu \mathrm{mol} / \mathrm{l})$ were well extracted and reextracted, but they were eluted from diethylaminoethyl-cellulose after vanilmandelic acid and homovanillic acid. Phenolic acids like 3,4-dihydroxymandelic acid ( $\leqslant 6.9 \mu \mathrm{mol} / 1)$ and 3,4-dihydroxyphenylacetic acid were not eliminated by the preseparation, but they did not interfere, because they were well separated by high-performance liquid chromatography.

\section{Method comparison}

The comparison of the present method vs. the procedure of Pisano $(1,2)$ resulted in a good correlation $(r=0.931)$. The regression line: $\mathrm{y}=0.992 \mathrm{x}+0.072$ (abscissa $=$ photometric determination) was calculated from 20 measurements (fig. 1).

\section{Sensitivity}

The detection limit is based on the reproducibility of the peak height at low concentrations of vanilmandelic acid or homovanillic acid. For vanilmandelic acid or homovanillic acid concentrations lower than 2.5 or $2.6 \mu \mathrm{mol} / 1$, resp. $(=0.5 \mathrm{mg} / \mathrm{l})$ the coefficient of variation was lower than $10 \%(n=8)$. At lower levels a precise evaluation was not possible, because the peak-height became smaller than $1 \mathrm{~cm}$. In 4 samples containing $1.1 \mu \mathrm{mol} / 1(\Leftrightarrow 0.21 \mathrm{mg} / \mathrm{l})$ vanilmandelic acid and $0.9 \mu \mathrm{mol} / 1(\hat{=} 0.17 \mathrm{mg} / 1)$ homovanillic acid coefficients of variation of $10.9 \%$ and $13.3 \%$ were found.
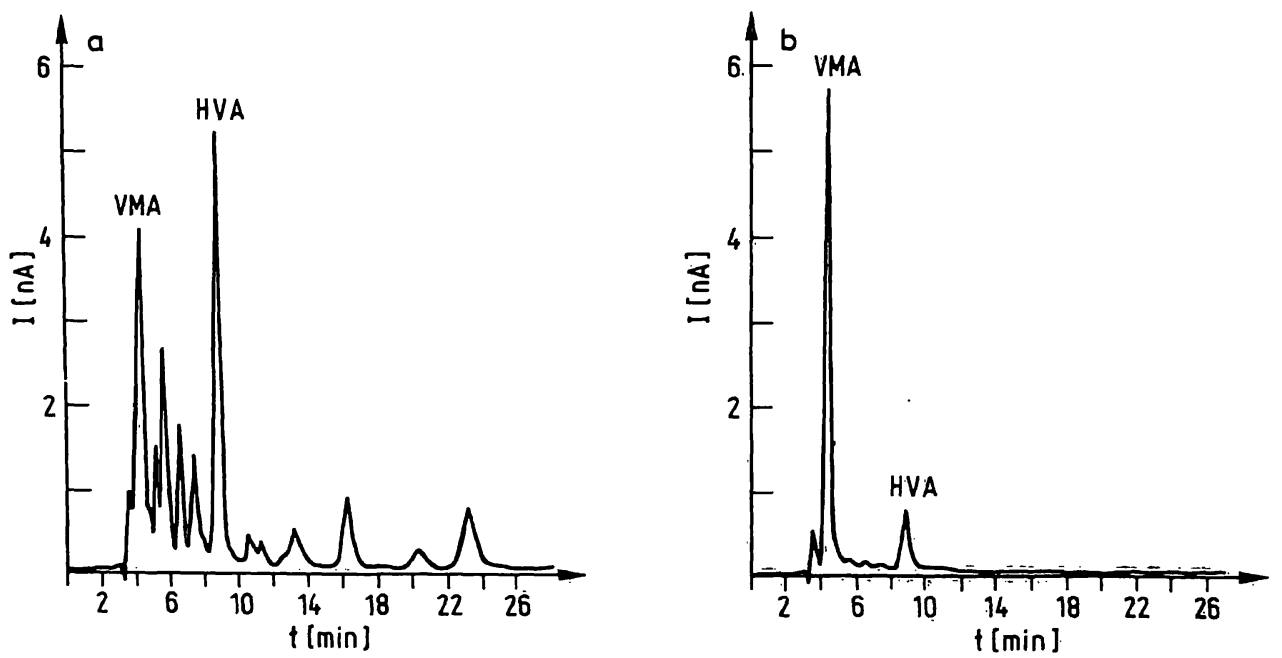

\section{References}

1. Pisano, J. J., Crout, J. \& Abraham, D. (1962) Clin. Chim. Acta 7, 285-291.

2. Wisser, H. \& Stamm, D. (1970) this J. 8, 21-26.

3. Rich, W., Johnson, E., Lois, L., Kabrä, P., Stafford, B. \& Marton, L. (1980) Clin. Chem. 26, 1492-1498.

4. Morrisey, J. L. \& Shihabi, Z. K. (1979) Clin. Chem. 25, 2043-2045.

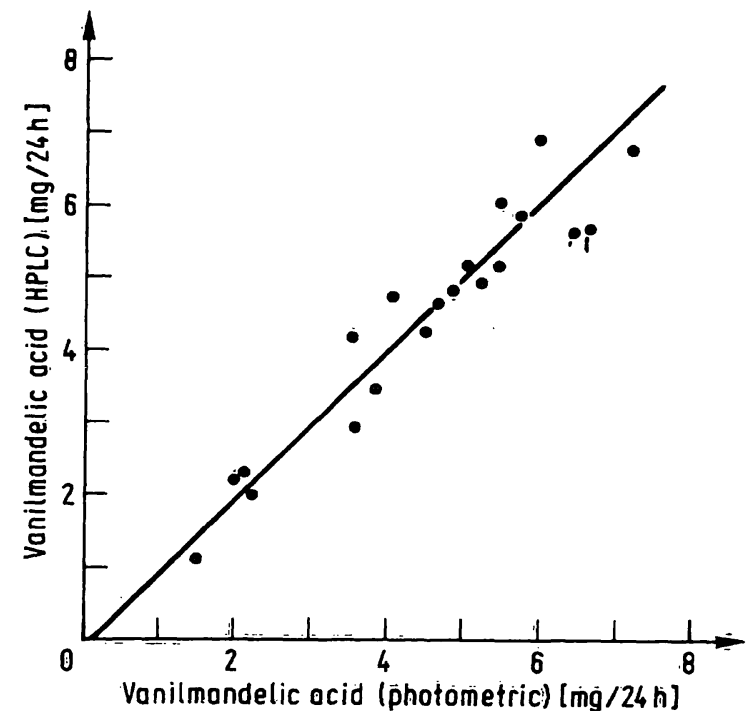

Fig. 1. Comparison of the HPLC-method and the photometric procedure; $\mathrm{y} \equiv 0.992 \times 0.072, \mathrm{r}=0.931, \mathrm{n}=20$.

\section{Application of the Method}

Figure 2 shows a chromatógràm of urine samples of (ä) a healthy man and (b) a patient with a pheochromócytoma (diluted $1: 10$ ). The urinary excretion of vanilmandelic acid - determined with the procedure of Pisano - was $23.2 \mu \mathrm{mol} / 24 \mathrm{~h}(\hat{=} 4.6 \mathrm{mg} / 24 \mathrm{~h}$ ) for the

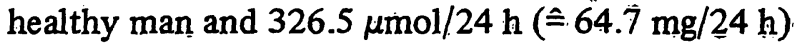
for the patient with pheochromocytoma. The corresponding values - determined by HPLC and ampero: metric detection - were $23.2 \mu \mathrm{mol} / 24 \mathrm{~h}(\hat{=} 4.6 \mathrm{mg} / 24 \mathrm{~h})$ and $284.1 \mu \mathrm{mol} / 24 \mathrm{~h}(\hat{\Xi} 56.3 \mathrm{mg} / 24 \mathrm{~h})$ for the vanilmandelic acid and $25.3 \mu \mathrm{mol} / 24 \mathrm{~h}(\hat{=} 4.6 \mathrm{mg} / 24 \mathrm{~h})$ and $70.8 \mu \mathrm{mol} / 24 \mathrm{~h}(\approx 12.9 \mathrm{mg} / 24 \mathrm{~h}$ ) for the homovanillic acid.
Fig. 2. Chromatogram of urine of a healthy man (a) and of a patient with pheochromocyitoman (diluted 1:10, b). VMA $=$ Vanilmandelic acidd HVA $=$ Homọòàillic acid
5. LaBrosse, E. H., Com-Nougue, Catherin, Zucker, J.-M., Comoy, E., Bohuon, L., Lemerle, J. \& Schweisguth, Odice (1980) Cancer Res. $40,1995=2001$.

W. Bauersfeld

Department of Clinical Chemistry

Robert-Bosch-Krankenhaus

Auerbachstr. 110

D-7000 Stụtgtgart 50 